\title{
Changes of olfactory abilities in relation to age: odor identification in more than 1400 people aged 4 to 80 years
}

\author{
A. Sorokowska • V. A. Schriever • V. Gudziol - C. Hummel • \\ A. Hähner · E. Iannilli $\cdot$ C. Sinding $\cdot$ M. Aziz $\cdot$ H. S. Seo • \\ S. Negoias $\cdot$ T. Hummel
}

Received: 5 May 2014/ Accepted: 28 August 2014/Published online: 20 September 2014

(C) The Author(s) 2014. This article is published with open access at Springerlink.com

\begin{abstract}
The currently presented large dataset $(n=1,422)$ consists of results that have been assembled over the last 8 years at science fairs using the 16-item odor identification part of the "Sniffin' Sticks". In this context, the focus was on olfactory function in children; in addition before testing, we asked participants to rate their olfactory abilities and the patency of the nasal airways. We reinvestigated some simple questions, e.g., differences in olfactory odor identification abilities in relation to age, sex, self-ratings of olfactory function and nasal patency. Three major results evolved: first, consistent with previously published reports, we found that identification scores of the youngest and the oldest participants were lower than the scores obtained by people aged 20-60. Second, we observed an age-related increase in the olfactory abilities of children. Moreover, the self-assessed olfactory abilities were related to actual performance in the smell test, but only in adults, and selfassessed nasal patency was not related to the "Sniffin" Sticks" identification score.
\end{abstract}

A. Sorokowska $(\bowtie) \cdot$ V. A. Schriever · V. Gudziol ·

C. Hummel - A. Hähner - E. Iannilli · C. Sinding - M. Aziz .

H. S. Seo - S. Negoias - T. Hummel

Department of Otorhinolaryngology, TU Dresden,

Fetscherstrasse 74, 01307 Dresden, Germany

e-mail: sorokowska@gmail.com

\section{A. Sorokowska}

Institute of Psychology, University of Wroclaw, ul. Dawida 1, 50-527 Wroclaw, Poland

\section{H. S. Seo}

Department of Food Science, University of Arkansas, Fayetteville, USA

\section{S. Negoias}

Department of Otorhinolaryngology, University of Bern, Bern, Switzerland
Keywords Epidemiology $\cdot$ Smell $\cdot$ Sex $\cdot$ Age $\cdot$ Nose . Olfaction · Children

\section{Introduction}

Olfaction allows us to detect subtle changes in our physical and social environment $[1,2]$, but sensitivity of this sense varies across individuals [3]. There exist many tests for the assessment of olfactory function [4]; the "Sniffin' Sticks" test [SST; Burghart Messtechnik, Wedel, Germany; 5-7] is one of the most popular tools.

Sniffin' Sticks test is a test of nasal chemosensory performance based on a battery of odor-filled felt-tip pens, which are briefly opened to release certain smells. It consists of three tests of olfactory function-odor threshold, odor discrimination, and odor identification; previous works have shown the test-retest reliability of this kit [5, 7]. The normative data of the SST have been established in many countries all over the world [e.g., 6, 8-10] and the SST has already been used in more than 500 studies.

The currently presented large dataset $(n>1,400)$ consists of results that have been assembled over the last 8 years at science fairs using the 16-item odor identification part of the SST. Previous reports on the Sniffin' Sticks have not been consistent on the existence of sex differences in olfactory sensitivity (e.g., Hummel and collaborators [6] observed sex differences only in some age groups, and Sorokowska and Hummel did not find such differences [10]). Also, although previous reports suggested that olfactory sensitivity of children and older people is lower than sensitivity of young and middle-aged adults [6-10], they have not tested age-related differences in olfactory function of more specific age groups, but rather defined "children" as individuals below 15 years of age and "older 
people" as people aged above 55. In addition, the seemingly lower olfactory abilities of children have not been fully explored. In this context, the focus was on olfactory function in this age group. Here it is important to note that the current analysis was not meant to produce normative data, but the emphasis was on the reinvestigation of five simple questions that have been addressed in previous studies: (1) Does the ability of odor identification differ by gender? (2) Is there a decrease of olfactory function with age? (3) Do the odor identification scores change in childhood? (4) Is self-assessed olfactory sensitivity related with odor identification ability? and (5) Is self-assessed nasal patency related with odor identification ability?

\section{Materials and methods}

\section{Participants}

In total data were obtained from 1,422 subjects aged $4-80$ (356 children aged $<16,203$ girls and 153 boys; 696 young adults aged 16-35, 439 women and 257 men; 243 middleaged adults aged 36-55, 152 women and 91 men; and 127 older adults aged $>55,76$ women and 51 men).

Data were collected during various scientific fairs held at the Medical Faculty Campus of the Technical University Dresden (Dresden, Germany). A group of Polish people from Wroclaw $(n=28)$ was also tested to expand the group of the oldest participants (70+). All subjects confirmed that they were in good health. Investigations were performed according to the Declaration of Helsinki and approved by the local ethics committee (EK327082013).

\section{Procedure}

First, the participants were asked to rate their olfactory sensitivity and nasal patency on two 5-point Likert scales ranging from 1 (very good) to 5 (very bad); 3 indicated average. Afterward, trained experimenters assessed olfactory function of participants using the SST 16-item odor identification subtest (Burghart Messtechnik, Wedel, Germany) according to methods published previously [5, 6]. Participants were asked to identify each presented odor from a list of four descriptors; we decided to use only verbal descriptors since previous results have indicated that pictures may not be very helpful in an odor identification task in adults [5]. In children with reading difficulties, the verbal descriptors were read to them by the experimenter. The number of correct answers constituted the identification score. The interval between odor presentations was approximately $20 \mathrm{~s}$. Olfactory function was assessed birhinally.
Statistical analyses

To explore the olfactory function (defined as the identification score in SST) in relation to age and sex of the subjects, data were submitted to analyses of variance (ANOVA) using the general linear model with main factors: "age group" (defined below) and "sex" (men, women), followed by post hoc Bonferroni $t$ tests. We performed three separate analyses on different age groupings:

(a) To compare our findings to previous reports [5, 6], we separated the subjects into four age groups (AD): group A: 5-15 years, group B: 16-35 years, group C: $36-55$ years, group D: $>55$ years;

(b) To further explore the age-related differences in odor sensitivity, we divided our participants on 8 age groups-according to decades;

(c) We also analyzed the age-related differences in scores of children (aged 15 or less) in detail-their results were analyzed year by year.

Furthermore, subjects were separated into three groups according to (1) their self-assessed olfactory sensitivity and to (2) their nasal patency (I to III): I - subjects who assessed their sense of smell/nasal patency as bad or very bad; II - subjects who assessed their sense of smell/nasal patency as average; and III - subjects who rated their sense of smell/nasal patency as good or very good. The relationships between (1) self-assessed sensitivity and odor identification score, and (2) nasal patency and odor identification score were analyzed using one-way analyses of variance (ANOVA) with factor "self-assessed sensitivity" (in the first analysis) and "nasal patency" (in the second analysis) using Bonferroni post hoc tests. Additionally, the relationship between self-assessed olfactory abilities and self-rated nasal patency was analyzed using Pearson's $r$ correlation.

We undertook two-tailed tests throughout, using STATISTICA ver10 (StatSoft, Inc., Tulsa, USA) with $p<0.05$ as the level of significance.

\section{Results}

Effects of sex and age on odor identification

Results for 4 age groups $(A-D)$

Descriptive statistics for groups A, B, C, and D are shown in Table 1.

We found significant differences in odor identification abilities between the age groups [significant main effect of "age": $F(3,1,414)=56.3, \quad p<0.001]$. Post hoc 
Table 1 Descriptive statistics of the SST identification scores for subjects separated into 4 age groups ( $n$ number of subjects, $M$ mean, $S D$ standard deviation, female vs. male significance of difference between scores of females and males in a given age group)

\begin{tabular}{lllllllllll}
\hline Age group & $\begin{array}{l}\text { Age range } \\
\text { (years) }\end{array}$ & $n$ & $\begin{array}{l}\text { Score } \\
M\end{array}$ & $\begin{array}{l}\text { Score } \\
S D\end{array}$ & Median & $\begin{array}{l}\text { 10th } \\
\text { percentile }\end{array}$ & $\begin{array}{l}\text { 90th } \\
\text { percentile }\end{array}$ & $\begin{array}{l}\text { Female } \\
\text { score } M\end{array}$ & $\begin{array}{l}\text { Male } \\
\text { score } M\end{array}$ & $\begin{array}{l}\text { Female vs. } \\
\text { male } p\end{array}$ \\
\hline $\begin{array}{l}\text { A (young } \\
\text { children) }\end{array}$ & $<16$ & 356 & 12.45 & 2.20 & 13 & 9 & 15 & 12.64 & 12.19 & 0.79 \\
$\begin{array}{l}\text { B (young adults) } \\
\text { C (middle-aged }\end{array}$ & $16-35$ & 696 & 13.77 & 1.62 & 14 & 12 & 16 & 13.83 & 13.67 & 1 \\
$\quad \begin{array}{l}\text { adults) } \\
\text { D (older adults) }\end{array}$ & $>55$ & 243 & 13.79 & 1.68 & 14 & 12 & 16 & 13.86 & 13.66 & 1 \\
\hline
\end{tabular}

Bonferroni $t$ tests showed that the groups A and D scored lower than groups $\mathrm{B}$ and $\mathrm{C}(p<0.001)$. All the remaining differences were not significant (all $p>0.05$ ). We did not observe any significant effect of sex for the identification score $[F(3,1,414)=2.72, p=0.10]$. Also, we found no significant interaction effect of the factors "sex" and "age group" $[F(3,1,414)=0.61, p=0.61]$. To further investigate the sex differences within particular age groups, we conducted four independent samples $t$ tests. The differences between men and women were not significant in either of the age groups (see Table 1 for detailed results; all $p s>0.05)$.

\section{Results for 8 age groups (1-8)}

Descriptive statistics for 8 age groups (decades) can be found in Table 2.

We found a significant interaction effect "sex $\times$ age" $[F(7,1,406)=2.31 ; p=0.02]$, but the effect size was low $\left(\eta^{2}=0.01\right)$ and post hoc Bonferroni tests revealed no significant sex differences within particular age groups (detailed results of men and women can be found in Table 2).

Comparison of the scores of groups $1-8$ revealed significant differences $[F(7,1,406)=32.6, p<0.001]$ between the age groups. Post hoc Bonferroni tests showed that scores of age group 8 (people aged 70+) were significantly lower than scores of any other group, except for the youngest $(<9)$ children (all $p<0.001)$. Group 1 (children aged 9 and younger) scored significantly lower ( $p<0.001$ ) than age groups 2-6 (people aged 10-59). Group 7 (people aged 60-69) scored significantly lower (all $p<0.001$ ) than age groups 3-5 (people aged 20-49). Additionally, the scores of children from the age group 2 (aged 10-19) were significantly lower $(p=0.02)$ than the scores of people from age group 3 (aged 20-29). All the other differences were not significant (all $p>0.05$; see Fig. 1). There was no significant main effect of "sex" $\left[F(1,1,406)=2.45 ; p=0.12 ; \eta^{2}=0.14\right]$.

\section{Age-related differences in olfactory function of children}

Descriptive statistics of children's scores are presented in Table 3.

We found a significant interaction effect "sex $\times$ age" $[F(11,332)=2.00 ; p=0.03]$, but the effect size was extremely low $\left(\eta^{2}=0.06\right)$ and post hoc Bonferroni tests revealed no significant differences between boys and girls of any ages. Comparison of the scores obtained for children of different ages revealed significant differences between the age groups $\left[F(11,343)=4.58 ; p<0.001 ; \eta^{2}=0.13\right]$. Post hoc Bonferroni tests indicated that scores of children

Table 2 Descriptive statistics of the SST identification scores for subjects separated into 8 age groups ( $n$ number of subjects, $M$ mean, $\min$ minimum, max maximum, $S D$ standard deviation)

\begin{tabular}{|c|c|c|c|c|c|c|c|c|c|c|c|c|c|}
\hline $\begin{array}{l}\text { Age } \\
\text { group }\end{array}$ & $\begin{array}{l}\text { Age range } \\
\text { (years) }\end{array}$ & $\begin{array}{l}\text { Total } \\
N\end{array}$ & $\begin{array}{l}\text { Score } \\
M\end{array}$ & $\begin{array}{l}\text { Score } \\
\text { min }\end{array}$ & $\begin{array}{l}\text { Score } \\
\max \end{array}$ & $\begin{array}{l}\text { Score } \\
S D\end{array}$ & Median & $\begin{array}{l}\text { 10th } \\
\text { percentile }\end{array}$ & $\begin{array}{l}\text { 90th } \\
\text { percentile }\end{array}$ & $\begin{array}{l}\text { Females } \\
N\end{array}$ & $\begin{array}{l}\text { Female } \\
\text { score } M\end{array}$ & $\begin{array}{l}\text { Males } \\
n\end{array}$ & $\begin{array}{l}\text { Male } \\
\text { score } M\end{array}$ \\
\hline 1 & 4-9 & 185 & 11.88 & 5 & 16 & 2.35 & 12 & 9 & 15 & 104 & 12.01 & 81 & 11.72 \\
\hline 2 & 10-19 & 249 & 13.29 & 6 & 16 & 1.80 & 14 & 11 & 15 & 157 & 13.53 & 92 & 12.88 \\
\hline 3 & $20-29$ & 525 & 13.79 & 5 & 16 & 1.53 & 14 & 12 & 16 & 333 & 13.88 & 192 & 13.63 \\
\hline 4 & $30-39$ & 137 & 13.71 & 3 & 16 & 2.00 & 14 & 12 & 16 & 76 & 13.47 & 61 & 14.00 \\
\hline 5 & $40-49$ & 157 & 13.83 & 9 & 16 & 1.52 & 14 & 12 & 16 & 99 & 14.00 & 58 & 13.55 \\
\hline 6 & $50-59$ & 71 & 13.37 & 6 & 16 & 2.20 & 14 & 11 & 16 & 43 & 13.42 & 28 & 13.29 \\
\hline 7 & $60-69$ & 54 & 12.48 & 2 & 16 & 2.71 & 13 & 10 & 15 & 29 & 12.10 & 25 & 12.92 \\
\hline 8 & $70-80$ & 44 & 11.05 & 3 & 16 & 2.92 & 11.5 & 7 & 15 & 29 & 11.48 & 15 & 10.20 \\
\hline SUM & & 1,422 & & & & & & & & 870 & & 552 & \\
\hline
\end{tabular}


Fig. 1 Age-related differences in SST identification scores (means indicated by circles and standard deviations indicated by bars are shown for age groups 1-8 in decades; For the details of age-decade, please see Table 2)

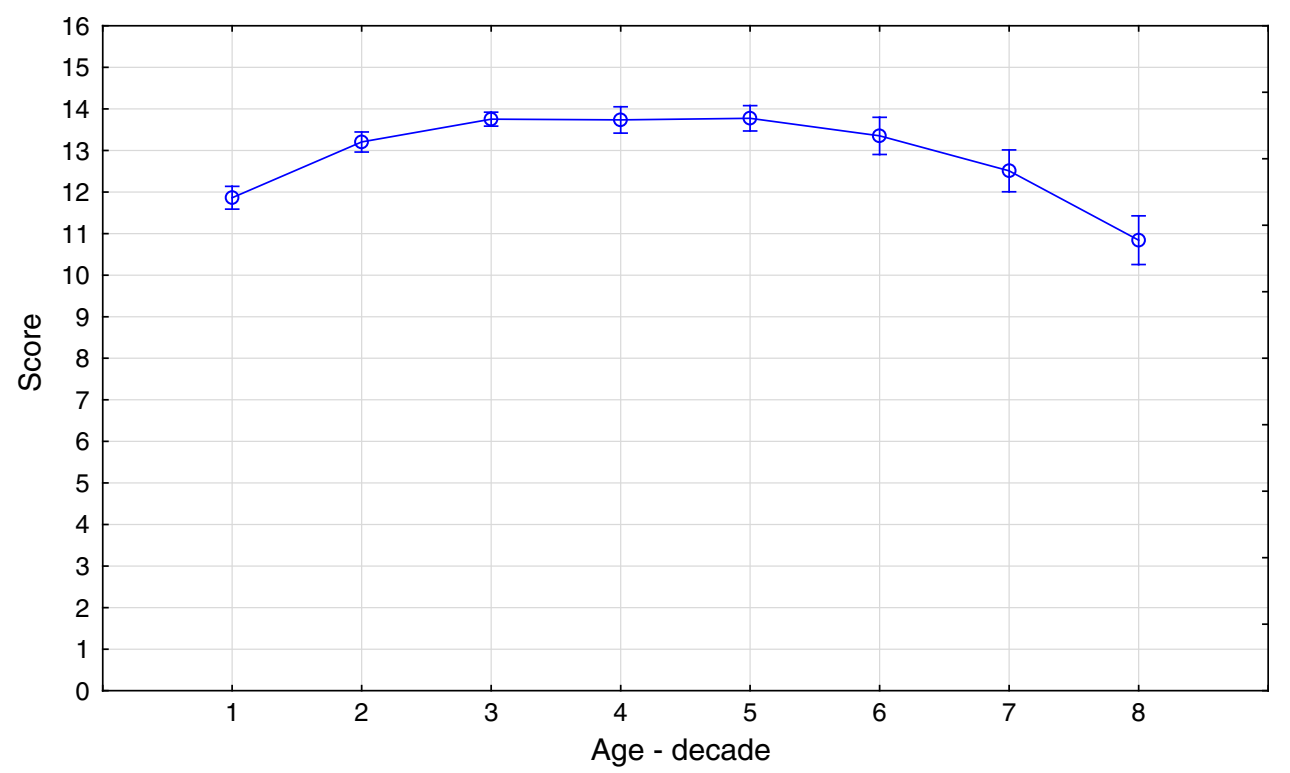

Table 3 Descriptive statistics of SST identification test results in children ( $n$ number of subjects, $M$ mean, $S D$ standard deviation)

\begin{tabular}{llll}
\hline $\begin{array}{l}\text { Age } \\
\text { (years) }\end{array}$ & $n$ & $\begin{array}{l}\text { Score } \\
M\end{array}$ & $\begin{array}{l}\text { Score } \\
S D\end{array}$ \\
\hline 4 & 11 & 11.45 & 0.92 \\
5 & 10 & 10.70 & 0.94 \\
6 & 22 & 10.73 & 0.48 \\
7 & 33 & 11.67 & 0.38 \\
8 & 49 & 12.22 & 0.31 \\
9 & 60 & 12.42 & 0.29 \\
10 & 39 & 12.36 & 0.31 \\
11 & 36 & 13.64 & 0.26 \\
12 & 40 & 13.08 & 0.29 \\
13 & 25 & 13.20 & 0.29 \\
14 & 18 & 12.94 & 0.56 \\
15 & 13 & 13.38 & 0.47 \\
\hline
\end{tabular}

aged 6 were significantly lower than scores of children aged 11-15 (all $p \mathrm{~s}<0.05)$. Children aged 11 scored significantly higher $(p<0.01)$ than children aged $5-7$. We found no significant main effect of "sex" $[F(1,332)=$ $\left.2.30 ; p=0.13 ; \eta^{2}=0.01\right]$.

As previous reports on normative values in the SST rather present children as one, homogenous group of people below 15 years of age [5-9], the presented results of young children can be used as a guideline for future experiments.

Relationship between self-assessed sensitivity and identification score

Out of all participants who took part in testing, 722 participants assessed their overall olfactory sensitivity and 710 people assessed their nasal patency. 258 people rated their sense of smell as good or very good, 385 as average, and 63 as bad or very bad. Furthermore, 258 people rated their nasal patency as good or very good, 371 as average, and 81 as bad or very bad.

Generally, the performance in the identification test did not depend on the self-assessed olfactory abilities of the participants $[F(2,703)=2.60, p=0.08$; one-way ANOVA] . However, this was due to a nonsignificant effect in the youngest age group, which suggests that only adults could accurately rate their smell. When only the results of people from age groups 2-4 were analyzed (477 participants aged $>15$ ), the effect of self-assessed olfactory abilities on identification score was significant $[F \quad(2,474)=6.22$, $p=0.002]$. Post hoc Bonferroni tests pointed toward significant differences between the groups. The results of the group who assessed their sense of smell as bad or very bad $(n=57$, $M=12.61$ ) were significantly lower than results of groups that assessed their smell as good or very good $(n=182$, $M=13.52, p=0.001)$ and scores of the group of average smellers $(n=238, M=13.36 p=0.009)$. However, the results of "good smellers" and "average smellers" were not significantly different. The participants' score in identification test was not dependent on their self-assessed nasal patency ( $p=0.57$, one-way ANOVA). This analysis could not be performed for separate age groups because there were no subjects in some subclasses (e.g., people below 16 who assessed their nasal patency as average). Self-ratings of olfactory sensitivity and nasal patency were significantly correlated $(r=0.31, p<0.001)$.

\section{Discussion}

The present investigation revealed the following major results: first, consistent with previously published reports 
$[5,6]$, we found that SST identification scores of the youngest and the oldest participant groups were lower than the scores obtained by people aged 20-60. Secondly, we observed an age-related increase in the olfactory abilities of children. Moreover, the self-assessed olfactory abilities were related to SST identification scores, but only in adults, and self-assessed nasal patency was not related to the SST identification score.

In line with previous work [10,11], performance of men and women in our sample was not significantly different which is in contrast to many publications (for review: [12]). As the currently used odor identification test is designed to be a relatively simple screening test, it might be not sufficient to detect subtle differences between subjects (and thus the sex differences). Also, some studies show that female superiority in terms of olfactory function decreases when men are provided with some help in the retrieval of odor names [13], so it is possible that generally the SST identification subtest might be equally easy or difficult for men and women.

As for the results concerning age-related differences in abilities to identify odors, our data revealed the same pattern of results like previous reports [e.g., 6, 14]. Generally, scores obtained in the oldest and the youngest subjects were decreased in comparison to the participants aged 20-60 years, with scores of the participants aged $\geq 70$ and $<10$ being the lowest. Numerous articles explain the deterioration of the sense of smell in old people (also termed "presbyosmia") [15-19]. Lower olfactory abilities might be a result of many factors, including neurodegenerative diseases or cumulative damage to the olfactory epithelium from repeated infections $[4,20]$. The reason for worse performance of children in the olfactory tests seems to be less clear and different than in the case of older people-it seems rather unlikely that they result from common causes of disorders in older age, especially when considering that olfactory disorders are relatively uncommon in children [21, 22]. However, the issue of children's poor olfactory performance has been analyzed in relatively few studies.

Generally, olfaction in children seems to be very good, including sensitivity to body odors [23-26]. Many studies have shown that children can detect, discriminate, and respond to odors and that they can do it starting from the very beginning of their lives. Olfaction might be an important source of information about food, environment, and people [for a review, 27]. Additionally, it is possible to perform olfactory classical conditioning in newborns, which suggests that the sense of smell is already fully functional during later stages of gestation [28]. Still, the children's sense of smell and/or their verbal abilities seem to develop with age $[27,29]$. Therefore, we suggest that the two sources of the age-related differences in olfactory performance of children are their knowledge of odors and their cognitive abilities.

First, performance in odor identification test relies on prior exposure to and familiarity with the target odors [30, 31] and provided response alternatives [33]. Generally, olfactory thresholds of children and young adults are not very different $[23,24]$. In the age range of $4-10$ years, abilities to name and recognize odors are less developed than those of adults [33], even though children have a substantial odor vocabulary [34]. Hence, the main source of the observed differences between children and adults could be the lack of the odor-specific knowledge in children.

Odor identification appears to be not only an indicator for olfactory function but also for cognitive abilities [15, $35,36]$. The ability to identify olfactory stimuli is significantly correlated with measures of memory, language, and other cognitive abilities [32, 37]; identification involves detection, discrimination, recognition, and retrieval of a name $[38,39]$. Therefore, the second source of the agerelated differences in olfactory performance in the identification test might be the level of development of cognitive abilities. It has been shown that individual's cognitive profile exerts a significant influence on higher order olfactory performance [37, 40, 41]. Also, increased olfactory identification was speculated to be a result of, among others, general semantic knowledge and good verbal skills [37, 41, 42], which are lower in younger children [43]. Additional limitations in the cognitive abilities of children which might be important in olfactory testing include difficulties in task comprehension and low concentration abilities [44].

Children almost always perform worse than adults on higher cognitive tasks, but the child's brain undergoes many changes throughout adolescence [for a review, 45]. In general, the sequence of changes taking place within the brain parallels cognitive development [45-49]. Regions related to primary, motor and sensory systems mature earliest, followed by cortices associated with basic language skills and spatial attention. Higher order association areas, responsible for integration of the primary sensorimotor processes and modulation of basic attention and language processes, seem to mature last [47, 48]. These developmental changes in cortical development have been found to correlate with behavioral performance measures [for a review, 45]. Therefore, lowered (but continuously developing) cognitive abilities of the children might be related to their performance in the identification task. This seems to be reflected in our results, depicting the gradual, age-related increase of the SST identification score in children.

There exist some specific olfactory tests used for children. Some of them-based on identification-resemble 
the "standard" tools for adults [50, 51], and some are modified a lot, to be more child friendly. For example, the 11-item smell wheel (Sensonics, Inc., Haddon Heights, NJ, USA, [21]) seems to be a game that consists of a rotating cardboard wheel containing microencapsulated "scratch and sniff" odorants and labels and the "Candy Smell Test" (CST, 23 aromatized sorbitol candies; [52]), based on retronasal smelling of aromas combined with a sweet taste is pleasant for children because they may enjoy candies. Still, these tests show the influence of age on the number of recognized odors. There exist also other measures, less dependent on identification and age of the patient, like the MODT (match-to-sample odorant discrimination task) created by Richman and collaborators [53]. However, great variability in the methodology of the existing tests reduces the effectiveness and reliability of their results [54].

The main focus of all the measures designed for children seemed to be brevity and easy application. It would be useful to work on a test that could be included in the standardized and established toolkit, like the SST [6]. There are a few issues that would need to be taken into account when creating such a test. First, children tend to repeat adults' statements and to respond affirmatively to positively phrased questions [44], thus special consideration has to be given to the phrasing of the questions. Second, although previous results have indicated that pictures may not be very helpful in an odor identification task [5], children might reach higher scores in olfactory tasks when verbal abilities are involved in the test to a lesser degree [e.g., 32, 55], and as they might have limited abilities to read [43], possible answers should be provided as both pictures and words. Also, although in odor identification tests adults and older children typically outperform younger children $[6,56,57]$, it is possible to find odors that are familiar to young children-e.g., in the smell wheel [21] bubblegum was well identified by participants of all ages; this suggests that the preselection of odorants for the child-friendly test needs to be particularly careful. Meanwhile, the best solution for proper olfactory examinations conducted by psychophysical methods seems to be the application of child-friendly tools for screening of the olfactory function, and usage of specific age-related norms in well-established methods like SST when longer and more detailed testing is necessary. In summary, the low scores of children might be an artifact, related to their poorer cognitive abilities and insufficient knowledge of odorants applied in the test. Odor identification tests require special adaptation before they can be administered in various populations $[10,14,58-60]$; however, most existing studies rather have not analyzed the problems associated with application of this test in children.

Interestingly, our participants could only assess their own olfaction to the extent that the group who assessed their sense of smell as bad or very bad scored lower in the test than the groups that assessed their smell as average, good, or very good. However, the scores of "average" and "good" groups were not significantly different. Our results and previous reports [61, 62] suggest that, especially in the case of people who think that their olfaction is good or very good, self-assessments of olfactory function are rather unreliable. In a study of Landis and collaborators [61] the self-assessments of olfactory abilities rather reflected changes of nasal airway patency than measurable olfactory function (but the ratings were accurate when they were performed after olfactory testing). The children in our study were not able to accurately assess their own olfactory sensitivity in any case. This might suggest that the question or the applied Likert scale were so difficult that they were not able to fully understand and complete the task. In future studies regarding self-assessed olfactory abilities in children it would be helpful to add, e.g., graphical emotion clipart to better illustrate the presented choice options.

The present study has some limitations. First, we tested only one olfactory modality and-due to time constraints-did not perform extended testing of various olfactory functions [63, 64]. Second, we only analyzed a very rough medical history and we did not perform any cognitive tests with the subjects. However, the participants did not report major diseases that would affect the olfactory system (e.g., acute or chronic nasal affections; diabetes mellitus, or liver disease) and as we collected the data during scientific fairs, selection of participants was rather biased toward well-informed, interested people who were very likely not to be demented.

In summary, our study showed that-consistent with previously published reports-identification scores of the youngest and the oldest participants were lower than the scores obtained by people aged 20-60. Furthermore, olfactory abilities of children were increasing with age and it seems that the sources of the age-related differences in identification test results relate to knowledge of odors and cognitive abilities. Additionally, we showed that the selfassessed olfactory abilities were related to actual performance in the smell test, but only in adults, and selfassessed nasal patency was not related to the "Sniffin' Sticks" identification score.

Acknowledgments We would like to thank our many colleagues who helped to collect data during the last years at the annual "Lange Nacht der Wissenschaft". During the project AS was supported by funds of Polish Ministry of Science and Higher Education (scholarship for years 2013-2016), Polish National Science Centre (ETIUDA scholarship \#2013/08/T/HS6/00408), and City Council of Wroclaw (Wincenty Stys scholarship).

Conflict of interest The authors declare that they have no conflict of interest. There was no external sponsor of the research. 
Open Access This article is distributed under the terms of the Creative Commons Attribution License which permits any use, distribution, and reproduction in any medium, provided the original author(s) and the source are credited.

\section{References}

1. Stevenson RJ (2010) An initial evaluation of the functions of human olfaction. Chem Senses 35:3-20

2. Sorokowska A, Sorokowski P, Szmajke A (2012) Does personality smell? Accuracy of personality assessments based body odour. Eur J Personal 26:496-503

3. Murphy C, Doty RL, Duncan HJ (2003) Clinical disorders of olfaction. In: Doty RL (ed) Handbook of olfaction and gustation, 2nd edn. Marcel Dekker, New York, pp 461-478

4. Doty RL (2009) The olfactory system and its disorders. Semin Neurol 29:74-81

5. Hummel T, Sekinger B, Wolf S, Pauli E, Kobal G (1997) "Sniffin' Sticks": olfactory performance assessed by the combined testing of odor identification, odor discrimination and olfactory threshold. Chem Senses 22:39-52

6. Hummel T, Kobal G, Gudziol H, Mackay-Sim A (2007) Normative data for the "Sniffin'Sticks" including tests of odor identification, odor discrimination, and olfactory thresholds: an upgrade based on a group of more than 3,000 subjects. Eur Arch Otorhinolaryngol 264:237-243

7. Kobal G, Hummel T, Sekinger B, Barz S, Roscher S, Wolf S (1996) "Sniffin' Sticks": screening of olfactory performance. Rhinology 34:222-226

8. Katotomichelakis M, Balatsouras D, Tripsianis G, Tsaroucha A, Homsioglou E, Danielides V (2007) Normative values of olfactory function testing using the 'Sniffin' Sticks'. Laryngoscope 117:114-120

9. Lin SH, Chu ST, Yuan BC, Shu CH (2009) Survey of the frequency of olfactory dysfunction in Taiwan. J Chin Med Assoc 72:68-71

10. Sorokowska A, Hummel T (2014) Polska wersja testu Sniffin' Sticks-adaptacja i normalizacja. Otolaryngol Pol. http://dx.doi. org/10.1016/j.otpol.2014.08.001 (in press)

11. Hummel T, Konnerth CG, Rosenheim K, Kobal G (2001) Screening of olfactory function with a four-minute odor identification test: reliability, normative data, and investigations in patients with olfactory loss. Ann Otol Rhinol Laryngol 110:976-981

12. Doty RL, Cameron EL (2009) Sex differences and reproductive hormone influences on human odor perception. Physiol Behav 97:213-228

13. Cain WS (1982) Odor identification by males and females: predictions vs. performance. Chem Senses 7:129-142

14. Doty RL, Applebaum SL, Zusho H, Settle RG (1985) A crosscultural study on sex differences in odor identification ability. Neuropsychologia 23:667-672

15. Cain WS, Gent JF (1991) Olfactory sensitivity: reliability, generality, and association with aging. J Exp Psychol 17:382-391

16. Doty RL, Kamath V (2014) The influences of age on olfaction: a review. Front Psychol 5:20. doi:10.3389/fpsyg.2014.00020

17. Hummel T, Barz S, Pauli E, Kobal G (1998) Chemosensory event-related potentials change as a function of age. Electroencephalogr Clin Neurophysiol 108:208-217

18. Murphy C, Schubert CR, Cruickshanks KJ, Klein BE, Klein R, Nondahl DM (2002) Prevalence of olfactory impairment in older adults. JAMA 288:2307-2312

19. Yousem DM, Maldjian JA, Hummel T, Alsop DC, Geckle RJ, Kraut MA, Doty RL (1999) The effect of age on odorstimulated functional MR imaging. Am J Neuroradiol 20:600-608
20. Breipohl W, Mackay-Sim A, Grandt D, Rehn B, Darrelmann C (1986) Neurogenesis in the vertebrate main olfactory epithelium. In: Breipohl W (ed) Ontogeny of olfaction. Springer, Berlin, pp 21-33

21. Cameron EL, Doty RL (2013) Odor identification testing in children and young adults using the smell wheel. Int $\mathbf{J}$ Pediat Otorhinolaryngol 77:346-350

22. Oozeer NB, Forbes K, Clement AW, Kubba H (2011) Management of paediatric olfactory dysfunction: how we do it. Clin Otolaryngol 36:494-499

23. Cain WS, Stevens JC, Nickou CM, Giles A, Johnston I, GarciaMedina MR (1995) Life-span development of odor identification, learning, and olfactory sensitivity. Perception 24:1457-1472

24. Hummel T, Bensafi M, Nikolaus J, Knecht M, Laing DG, Schaal B (2007) Olfactory function in children assessed with psychophysical and electrophysiological techniques. Behav Brain Res 180:133-138

25. Dorries KM, Schmidt HJ, Beauchamp GK, Wysocki CJ (1989) Changes in sensitivity to the odor of androstenone during adolescence. Dev Psychobiol 22:423-435

26. Sorokowska A (2013) Assessing personality using body odor: differences between children and adults. J Nonverbal Behav 37:153-163

27. Schaal B (1988) Olfaction in infants and children: developmental and functional perspectives. Chem Senses 13:145-190

28. Sullivan RM, Taborsky-Barba S, Mendoza R, Itano A, Leon M, Cotman C, Payne TF, Lott I (1991) Olfactory classical conditioning in neonates. Pediatrics 87:511-518

29. Ferdenzi C, Schaal B, Roberts C (2009) Family scents: developmental changes in the perception of kin body odor? J Chem Ecol 36:847-854

30. Goldman WP, Seamon JG (1992) Very long-term memory for odors: retention of odor-name associations. Am J Psychol 105:549-563

31. Richardson JT, Zucco GM (1989) Cognition and olfaction: a review. Psychol Bull 105:352-360

32. Frank RA, Dulay MF, Niergarth KA, Gesteland RC (2004) A comparison of the sniff magnitude test and the University of Pennsylvania smell identification test in children and nonnative English speakers. Physiol Behav 81:475-480

33. De Wijk RA, Cain WS (1994) Odor quality: discrimination versus free and cued identification. Percept Psychophys 56:12-18

34. Lehrner JP, Gluck J, Laska M (1999) Odor identification, consistency of label use, olfactory threshold and their relationships to odor memory over the human lifespan. Chem Senses 24:337-346

35. Murphy C, Gilmore MM, Seery CS, Salmon DP, Lasker BR (1990) Olfactory thresholds are associated with degree of dementia in Alzheimer's disease. Neurobiol Aging 11:465-469

36. Murphy C, Cain WS (1986) Odor identification: the blind are better. Physiol Behav 37:177-180

37. Hedner M, Larsson M, Arnold N, Zucco GM, Hummel T (2010) Cognitive factors in odor detection, odor discrimination, and odor identification tasks. J Clin Exp Neuropsychol 32:1062-1067

38. Chobor KL (1992) A neurolinguistic perspective of the study of olfaction. In: Serby MJ, Chobor KL (eds) Science of olfaction. Springer, New York, pp 355-376

39. Murphy C, Anderson JA, Markison S (1994) Psychophysical assessment of chemosensory disorders in clinical populations. Olfaction and taste XI. Springer, Japan, pp 609-613

40. Dulay MF, Gesteland RC, Shear PK, Ritchey PN, Frank RA (2008) Assessment of the influence of cognition and cognitive processing speed on three tests of olfaction. J Clin Exp Neuropsychol 30:327-337

41. Larsson M, Nilsson LG, Olofsson JK, Nordin S (2004) Demographic and cognitive predictors of cued odor identification: evidence from a population-based study. Chem Senses 29:547-554

42. Larsson M, Finkel D, Pedersen NL (2000) Odor identification influences of age, gender, cognition, and personality. J Geront B 55:304-310 
43. Cain K, Oakhill J, Bryant P (2004) Children's reading comprehension ability: concurrent prediction by working memory, verbal ability, and component skills. J Educ Psychol 96:31-42

44. Guinard J-X (2001) Sensory and consumer testing with children. Trends Food Sci Tech 11:273-283

45. Casey BJ, Tottenham N, Liston C, Durston S (2005) Imaging the developing brain: what have we learned about cognitive development? Trends Cogn Sci 9:104-110

46. Sowell ER, Peterson BS, Thompson PM, Welcome SE, Henkenius AL, Toga AW (2003) Mapping cortical change across the human life span. Nat Neurosci 6:309-315

47. Gogtay N, Giedd JN, Lusk L, Hayashi KM, Greenstein D, Vaituzis AC, Thompson PM (2004) Dynamic mapping of human cortical development during childhood through early adulthood. Proc Natl Acad Sci USA 101:8174-8179

48. Sowell ER, Thompson PM, Leonard CM, Welcome SE, Kan E, Toga AW (2004) Longitudinal mapping of cortical thickness and brain growth in normal children. J Neurosci 24:8223-8231

49. Giedd JN (2004) Structural magnetic resonance imaging of the adolescent brain. Ann NY Acad Sci 1021:77-85

50. van Spronsen E, Ebbens FA, Fokkens WJ (2013) Olfactory function in healthy children: normative data for odor identification. Am J Rhinol Allergy 27:197-201

51. Dżaman K, Zielnik-Jurkiewicz B, Jurkiewicz D, Molińska-Glura M (2013) Test for screening olfactory function in children. Int $\mathbf{J}$ Pediatr Otorhinolaryngol 77:418-423

52. Renner B, Mueller CA, Dreier J, Faulhaber S, Rascher W, Kobal G (2009) The candy smell test: a new test for retronasal olfactory performance. Laryngoscope 119:487-495

53. Richman RA, Sheehe PR, Wallace K, Hyde JM, Coplan J (1995) Olfactory performance during childhood. II. Developing a discrimination task for children. J Pediatr 127:421-426

54. Moura RGF, Cunha DA, Gomes ACLG, Silva HJ (2014) Quantitative instruments used to assess children's sense of smell: a review article. Codas 26:96-101
55. Monnery-Patris S, Rouby C, Nicklaus S, Issanchou S (2009) Development of olfactory ability in children: sensitivity and identification. Dev Psychobiol 51:268-276

56. Cain WS, Stevens JC, Nickou CM, Giles A, Johnston I, GarciaMedina MR (1995) Life-span development of odor identification, learning, and olfactory sensitivity. Perception 24:1457-1473

57. Laing DG, Segovia C, Fark T, Laing ON, Jinks AL, Nikolaus J, Hummel T (2008) Tests for screening olfactory and gustatory function in school-age children. Otolaryngol Head Neck Surg 139:74-82

58. Konstantinidis I, Printza A, Genetzaki S, Mamali K, Kekes G, Constantinidis J (2008) Cultural adaptation of an olfactory identification test: the Greek version of Sniffin' Sticks. Rhinology 46:292-296

59. Shu CH, Yuan BC, Lin SH, Lin CZ (2007) Cross-cultural application of the Sniffin' Sticks odor identification test. Am J Rhinol 21:570-573

60. Thomas-Danguin T, Rouby C, Sicard G, Vigouroux M, Johansson A, Bengtzon A, Ormel W (2001) Odour identification and discrimination: Influence of culture and typicality on performance. Chem Senses 26:1062

61. Landis BN, Hummel T, Hugentobler M, Giger R, Lacroix JS (2003) Ratings of overall olfactory function. Chem Senses 28:691-694

62. Shu CH, Hummel T, Lee PL, Chiu CH, Lin SH, Yuan BC (2009) The proportion of self-rated olfactory dysfunction does not change across the life span. Am J Rhinol Allergy 23:413-416

63. Bahar-Fuchs A, Moss S, Rowe C, Savage G (2011) Awareness of olfactory deficits in healthy aging, amnestic mild cognitive impairment and Alzheimer's disease. Int Psychogeriatr 23:1097-1106

64. Djordjevic J, Jones-Gotman M, De Sousa K, Chertkow H (2008) Olfaction in patients with mild cognitive impairment and Alzheimer's disease. Neurobiol Aging 29:693-706 